\title{
3-D Electromagnetic Analysis of Armatures and Rails for High Launch Energy Applications
}

\author{
Hsing-Pang Liu and Michael C. Lewis \\ The University of Texas at Austin Center for Electromechanics
}

\begin{abstract}
Transient three-dimensional (3-D) electromagnetic analyses have been performed on armatures and rails which are intended to be used for high launch energy applications. Coupled magnetic and thermal diffusions were solved within moving armatures in both square bore and round bore rail launchers. Current, magnetic field, body force and temperature distributions in the armature and rail conductors were predicted and compared. The predicted mechanical and thermal loading outputs can be further used for launcher structural analysis and rail cooling design.
\end{abstract}

Keywords-railgun, electromagnetic analysis, high launch energy

\section{INTRODUCTION}

Accurate numerical simulation and modeling are crucial to designs that require high muzzle energy and low package parasitic mass. The importance of 3-D electromagnetic analysis on solid armatures and rails for railgun operations were described and reported in previous researches [1-3]. Research and commercial computer codes have been developed over the past ten to twenty years to address the electrical, mechanical and thermal phenomena involved in high energy railgun launching applications. These codes can be used, on a relatively accurate basis, to predict the complex electrical and structural behaviors of armatures and launchers during a very short period of sliding electrical contact. These numerical investigations can typically guide the armature and launcher designs to achieve a certain design goal without undergoing expensive and time-consuming testing.

In this paper, transient 3-D electromagnetic analyses performed on the solid armatures and rail launchers used for high energy launching are described and the analysis results, which include predictions of transient current, magnetic field, body force and temperature distributions in the armature and launcher conductors are presented. The coupled magnetic and thermal diffusions have been solved for armatures and rail launchers with both square and round bore geometries. The predicted mechanical and thermal loading outputs from the electromagnetic analyses can be further used for launcher structural analysis and rail cooling design.

\section{ANALYSIS TOOLS}

A research computer code EMAP3D (Electro-Mechanical Analysis Program in 3 Dimensions) [4-7], developed by Institute for Advanced Technology at The University of Texas at Austin, has been used to perform transient 3-D coupled electromagnetic and thermal diffusions within moving armatures in square bore and round bore rail launchers. Quite a few papers published in the past [3, 8-13] also used this research code in their electromagnetic analyses. EMAP3D has certain critical capabilities, such as coupled magnetic and thermal diffusions within moving conductors and temperature dependent material properties, which are generally not available in commercial software packages. Also EMAP3D has been parallelized to reduce computing time significantly. This electromagnetic code was run on a Texas Advanced Computing Center supercomputer Lonestar. The Lonestar cluster contains $7683.06 \mathrm{GHz}$ and $2563.2 \mathrm{GHz}$ Xeon processors. The system storage includes a 6.2-TB parallel I/O file system, 18-TB of local compute-node disk space, and 3-TB of common work space.

\section{ELECTROMAGNETIC ANALYSIS FOR A SQUARE-BORE RAIL LAUNCHER}

The first 3-D electromagnetic analysis is a quasi-static analysis, in which no motion and ideal contact at armature/rail interface have been assumed, for a launch package having a high launch energy in a square bore rail launcher. The armature and rails are made of AL7075 and chromium copper, respectively. The gun, armature, and muzzle currents are shown in Fig. 1. A 3-D quarter symmetry finite element model, which includes armature, rail, and air, has been constructed for the analysis, and the model is shown in Fig. 2. Temperaturedependent electrical conductivities, thermal conductivities, and specific heats were taken into account in the simulations.

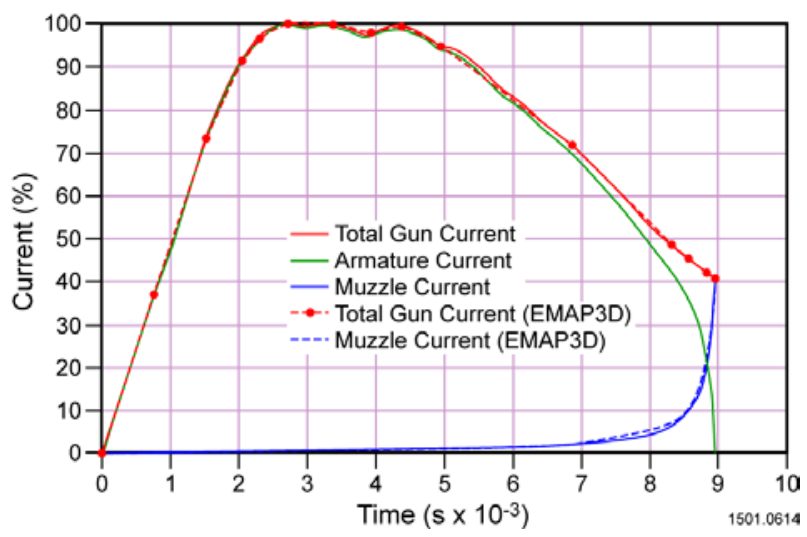

Figure 1. Gun, armature and muzzle current profiles 
The coupled electromagnetic and thermal diffusion analysis was solved in fourteen time steps. Maximum transient mechanical load occurs at the time where the peak gun current is reached. However, maximum armature and rail temperatures occur at the end of the gun current pulse. At the peak gun current, the predicted vector plots of current density and magnetic flux density distributions in the armature and rail are shown in Fig. 3. The predicted armature and rail temperature distributions at peak current and end of current pulse are displayed at two different viewing angles and plotted in Figs. 4 and 5. The melting temperatures of AL7075 and chromium copper are $640^{\circ} \mathrm{C}(913 \mathrm{~K})$ and $1073^{\circ} \mathrm{C}(1346 \mathrm{~K})$, respectively.
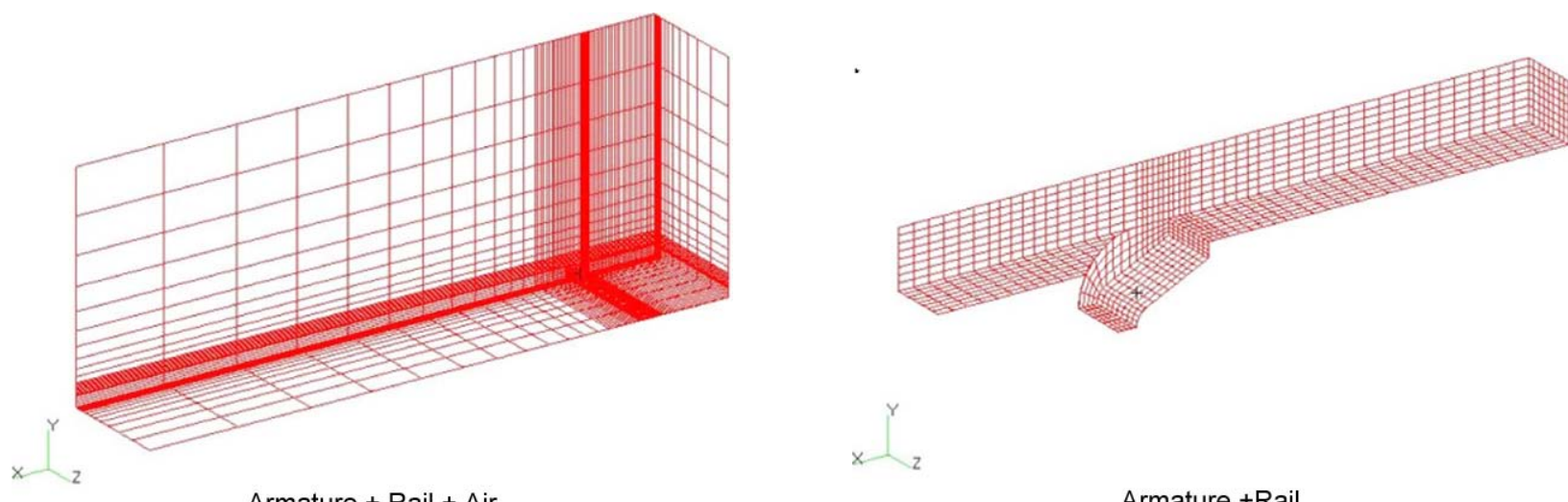

Armature + Rail + Air

Armature + Rail

Figure 2. 3-D quarter symmetry finite element model (square bore)

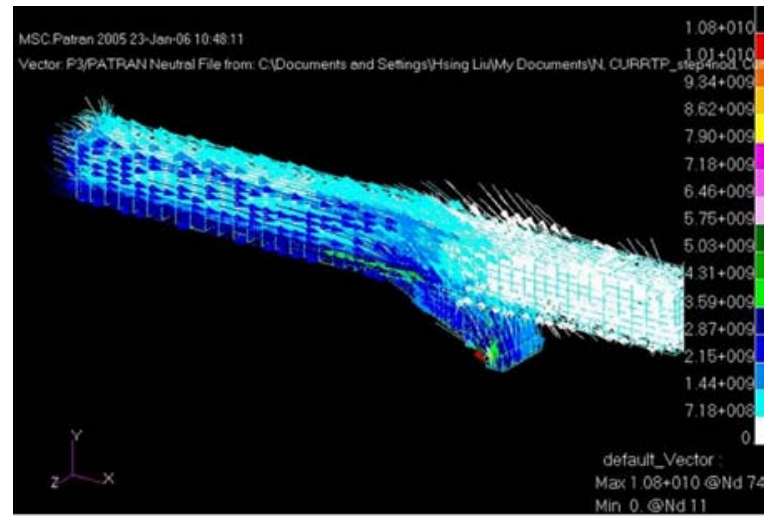

Current Density $\left(\mathrm{A} / \mathrm{m}^{2}\right)$

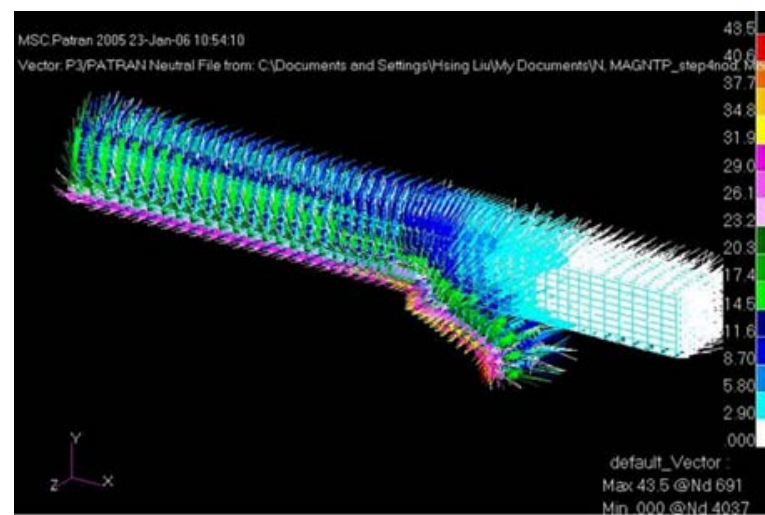

Magnetic Flux Density (Tesla)

Figure 3. Current density and magnetic flux density distributions at peak current (square bore)
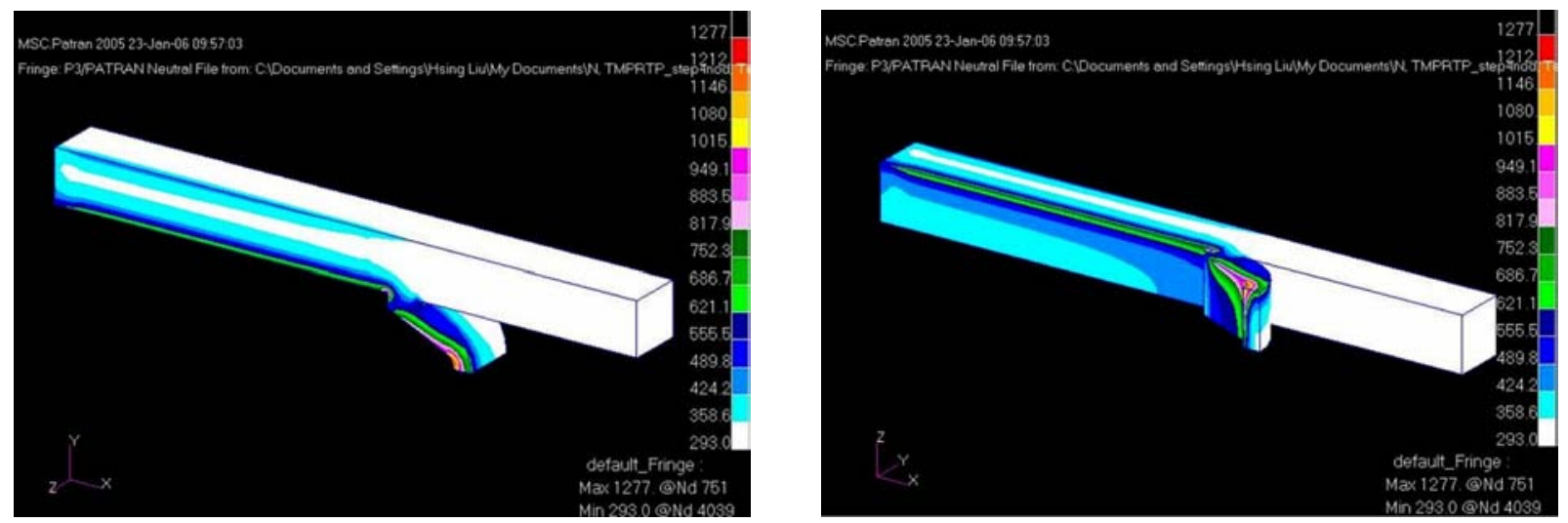

Figure 4. Temperature distribution (Kelvin) at peak current (square bore) 

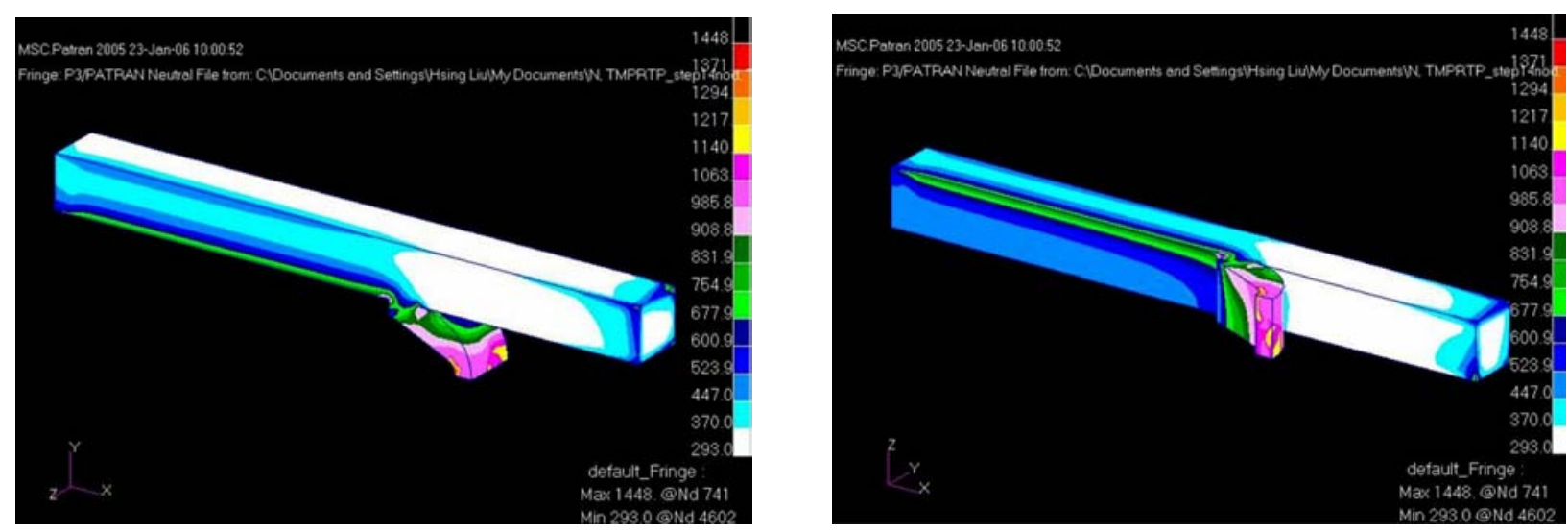

Figure 5. Temperature distribution (Kelvin) at end of current pulse (square bore)

Figs. 3 and 4 show high current density and high temperature are predicted at the leading-edge armature corners. Fig. 5 shows that melting is predicted at a significant portion of the armature root area which has high current densities due to less area to carry current.

\section{ELECTROMAGNETIC ANALYSIS FOR A ROUND- BORE RAIL LAUNCHER}

The second quasi-static 3-D electromagnetic analysis was performed on a launch package having a high launch energy in a round bore rail launcher. A low-conductivity material behind the rails was also included in the model to investigate its effect on forces and temperatures of the armature and rails. Since the armature geometry is quite complicated, the component geometries were built in SolidWorks and imported into Patran for EMAP3D model construction. Fig. 6 shows the armature geometry and Fig. 7 shows the 3-D quarter symmetry finite element model meshes. Gun current profiles are the same as those used in the first electromagnetic analysis. Temperaturedependent electrical conductivities, thermal conductivities, and specific heats of the armature and rail have been considered in the simulations. However, temperature-dependent material properties of the low-conductivity material are not available, only the room-temperature properties of this material were used in the analysis.

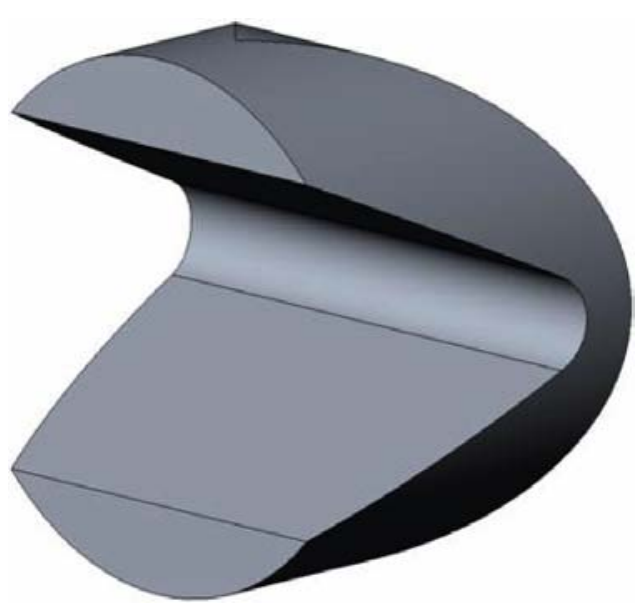

Figure 6. Armature geometry (round bore)
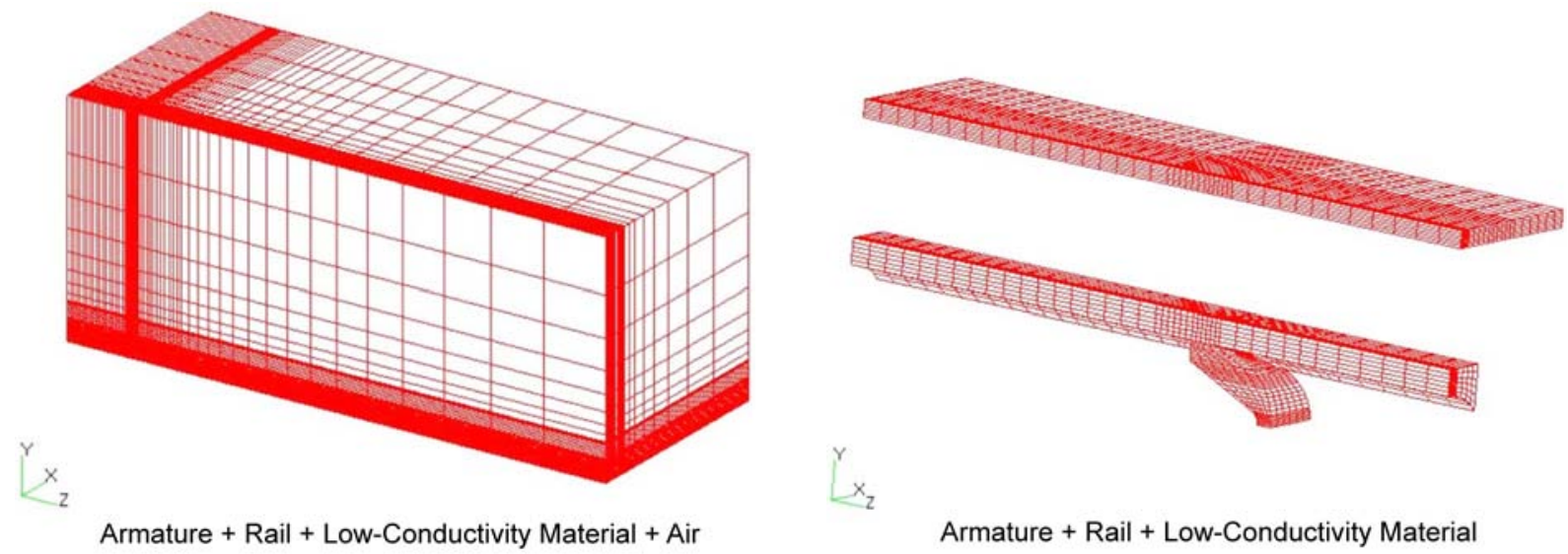

Figure 7. 3-D quarter symmetry finite element model (round bore) 
Again, the coupled electromagnetic and thermal diffusion analysis was solved in fourteen time steps. Inclusion of the low-conductivity material made the analysis convergent solutions difficult due to low electrical conductivity as compared to those of the copper rail and aluminum armature. Also, the model element qualities were not optimal because of the complex armature geometry. It is required to relax the EMAP3D convergence tolerances appreciably and increase the maximum number of iterations in each time step to get convergent solutions.
At the peak gun current, the predicted vector plots of current density and magnetic flux density distributions in the armature, rail and low-conductivity material are shown in Fig. 8. The predicted armature temperature distributions at the peak current and at the end of current pulse are plotted in Figs. 9 and 10. The predicted armature, rail and low-conductivity material temperature distributions at the peak current and at the end of current pulse are plotted in Figs. 11 and 12.

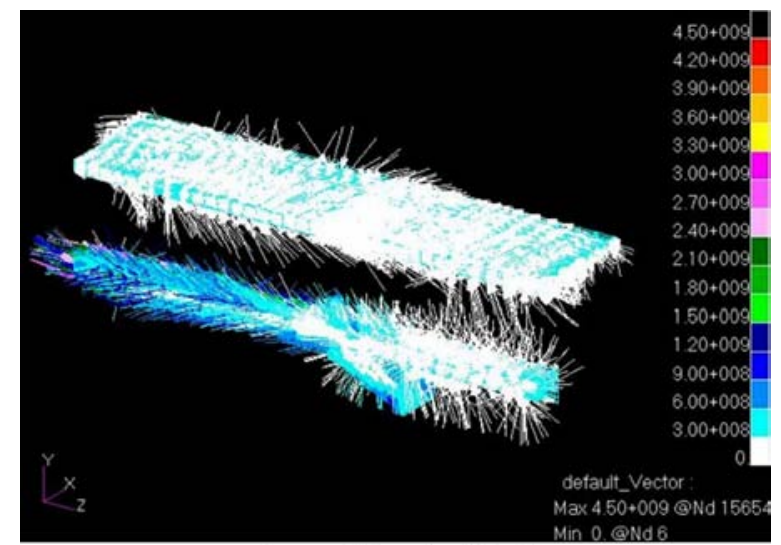

Current Density $\left(\mathrm{A} / \mathrm{m}^{2}\right)$

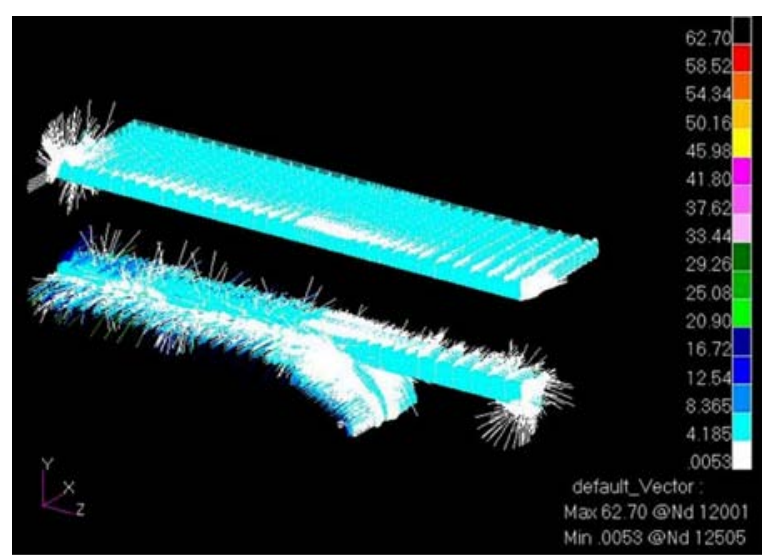

Magnetic Flux Density (Tesla)

Figure 8. Current density and magnetic flux density distributions in armature, rail and low-conductivity material at peak current (round bore)
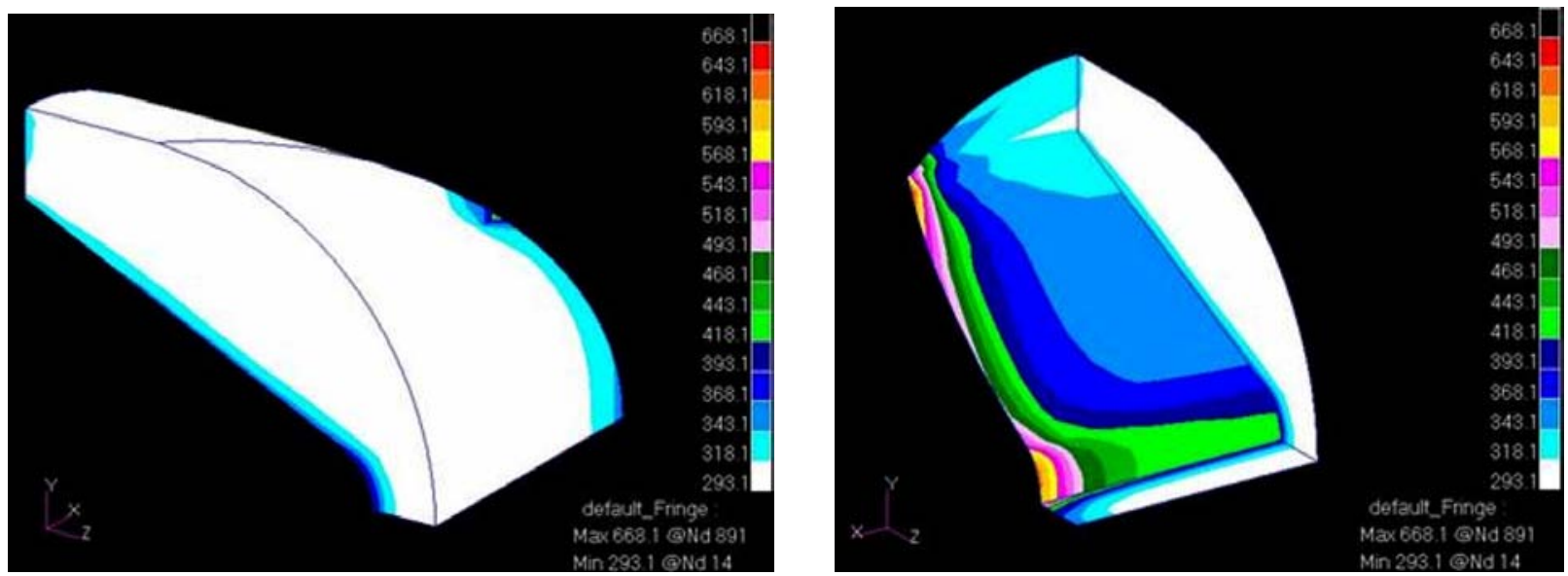

Figure 9. Armature temperature distribution (Kelvin) at peak current (round bore) 

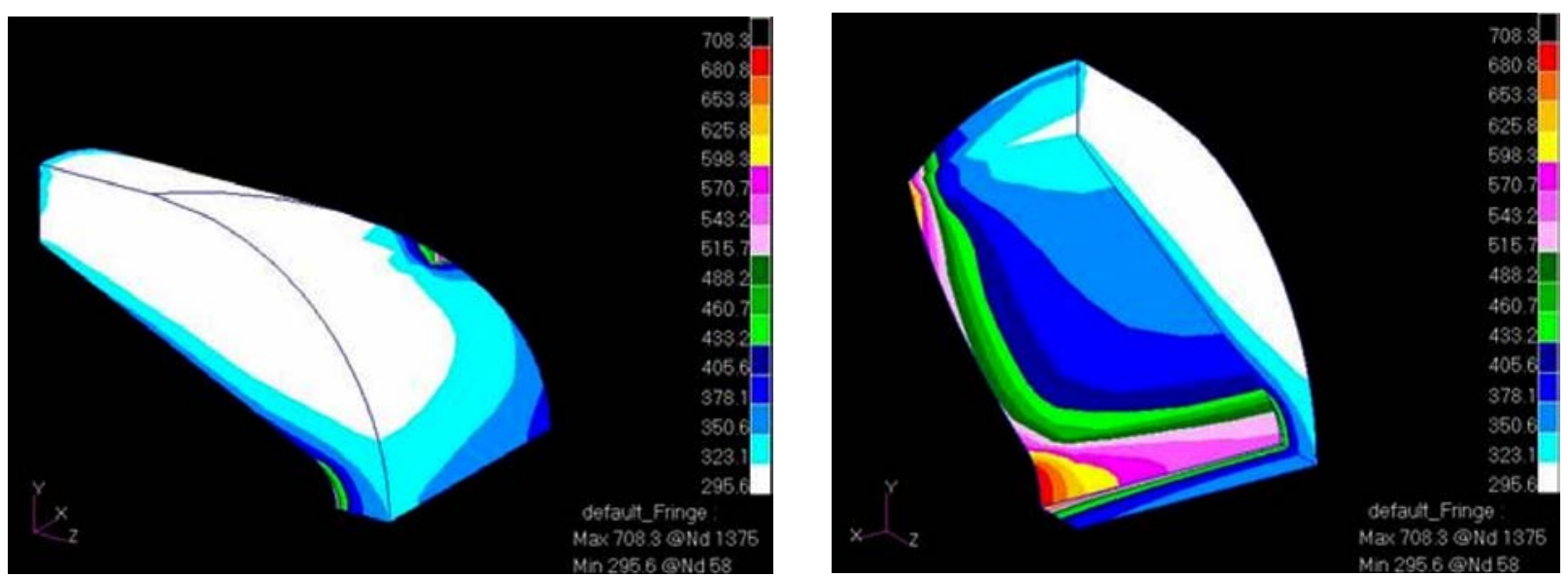

Figure 10. Armature temperature distribution (Kelvin) at end of current pulse (round bore)

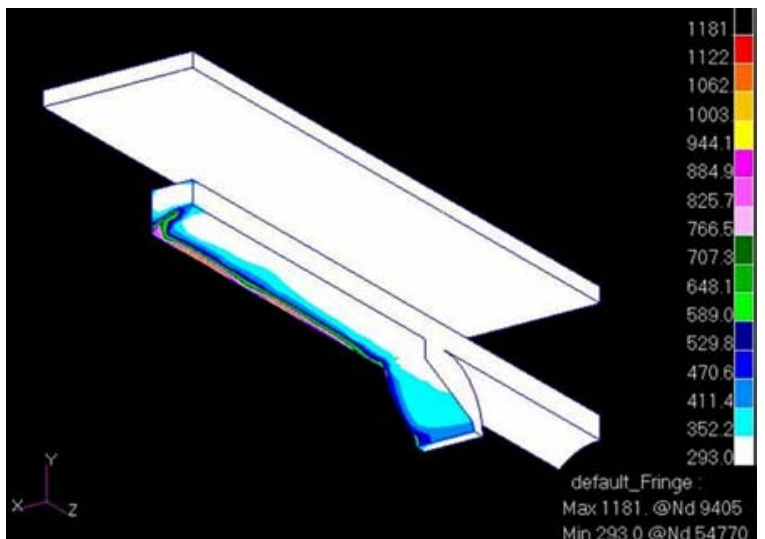

Figure 11. Temperature distribution (Kelvin) in armature, rail and lowconductivity material at peak current (round bore)

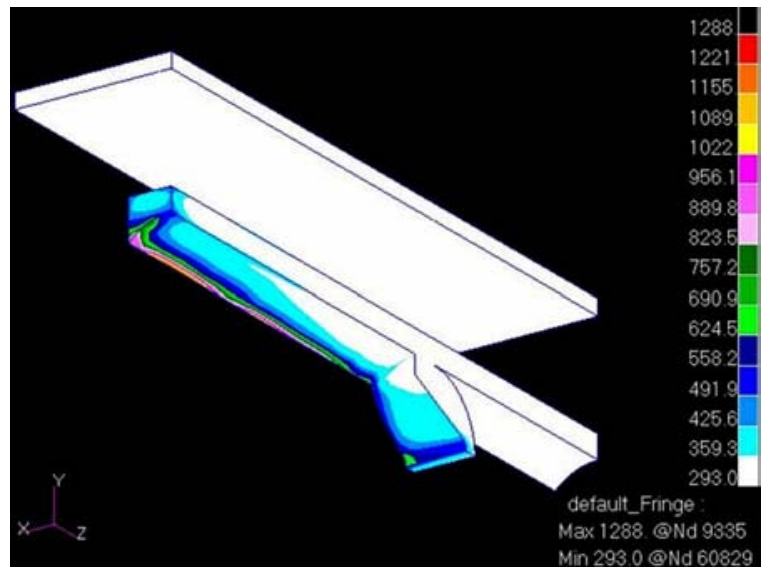

Figure 12. Temperature distribution (Kelvin) in armature, rail and lowconductivity material at end of current pulse (round bore)
The local non-continuous and less smooth temperature rises along the sharp-corner edge of the round bore rail, shown in Figs. 11 and 12, are considered to be primarily caused by the local extremely sharp corner, coarse local mesh densities, and less ideal element qualities for the sharp corner elements. The rail temperature rises along the inner corner edge of the square bore rail, shown in Figs. 4 and 5, are much clean and smooth because of the less-sharp corner and better local element qualities due to relatively simple armature geometry. By rounding the round bore rail corners and applying better local model mesh controls, the local current density and temperature rise disturbances along the rail's inner corner edge should disappear.

\section{CONCLUSIONS}

Examining the armature/rail current density and temperature distributions predicted by these two analyses, it can be found that, as expected, high current flows along the inner corner boundary edges of the rail and armature, and high local temperature rises are generated as a result. The high temperature developed in the armature root area is caused by its small current-flowing area. It is also found in the round bore electromagnetic analysis that the existence of the lowconductivity material has a non-negligible effect on the current densities, magnetic fluxes, body force densities and temperature rises generated in the armature and rail. Additional rail launcher power supply needs to be provided to compensate the eddy current loss generated in the low-conductivity material and allow the armature launching package to make performance. 


\section{ACKNOWLEDGMENTS}

The authors wish to thank Dr. Kuo-Ta Hsieh of the Institute for Advanced Technology at The University of Texas at Austin for his valuable assistance of using the EMAP3D code. This research was carried out under the ONR Railgun INP Program.

\section{REFERENCES}

[1] H. D. Yun and J. H. Price, "Electromagnetic and Structural Analyses of Electric Gun and Integrated Launch Package Systems," IEEE Transactions on Magnetics, vol. 31, pp. 253- 258, January 1995.

[2] R. C. Zowarka and H. D. Yun, "Railgun Solid Armature Scaling Model,” IEEE Transactions on Magnetics, vol. 33, pp. 169-174, January 1997.

[3] H-P. Liu, Y.L. Ting, R.C. Zowarka, and A. Alexander, "Electromagnetic and Structural Analyses of an Integrated Launch Package," IEEE Transactions on Magnetics, vol. 35, pp. 74-78, January 1999.

[4] EMAP3D User's Manual, Institute for Advanced Technology, The University of Texas at Austin, Version 1.2-0, Revised April 2005.

[5] K. T. Hsieh, "A Lagrangian Formulation for Mechanically, Thermally Coupled Electromagnetic Diffusive Processes with Moving Conductors," IEEE Transactions on Magnetics, vol. 31, pp. 604-609, January 1995.
[6] K. T. Hsieh and B. K. Kim, "Implementing Tri-Potential Approach in EMAP3D,” vol. 35, pp. 166-169, January 1999.

[7] K. T. Hsieh, "Parallelization of EMAP3D Based on Element-by-Element Jacobi Preconditioned Conjugate Gradient Method,” IEEE Transactions on Magnetics, vol. 39, pp. 139-141, January 2003.

[8] K. T. Hsieh and B. K. Kim, "3D Modeling of Sliding Electrical Contact," IEEE Transactions on Magnetics, vol. 33, pp. 237-239, January 1997.

[9] B. K. Kim and K. T. Hsieh, "Effect of Rail/Armature Geometry on Current Density Distribution and Inductance Gradient,” IEEE Transactions on Magnetics, vol. 35, pp. 413-416, January 1999.

[10] S. Levinson, J. V. Parker, K. T. Hsieh, and B. K. Kim, "Electrical and Thermal Effects of Rail Cladding," IEEE Transactions on Magnetics, vol. 35, pp. 417-422, January 1999.

[11] L. Rip, S. Satapathy, and K. T. Hsieh, "Effect of Geometry Change on the Current Density Distribution in C-Shaped Armatures," IEEE Transactions on Magnetics, vol. 39, pp. 72-75, January 2003.

[12] T. Benton, F. Stefani, S. Satapathy, and K. T. Hsieh, "Numerical Modeling of Melt- Wave Erosion in Conductors," IEEE Transactions on Magnetics, vol. 39, pp. 129-133, January 2003.

[13] K. T. Hsieh and S. Satapathy, "Plasticity Model in EMAP3D," IEEE Transactions on Magnetics, vol. 39, pp. 142-147, January 2003. 